\title{
Pesquisa-ação em Educação Ambiental
}

\author{
Marilia Freitas de Campos Tozoni-Reis ${ }^{1}$
}

resumo: Os trabalhos do Grupo de Discussão "Pesquisa e Ação" no IV Encontro de Pesquisa em Educação Ambiental - EPEA, em julho de 2007, partiram da discussão de um texto-base sobre essa metodologia de pesquisa que tratava de suas questões centrais. Essas discussões foram realizadas em dois encontros durante o evento e apontaram características, limites e perspectivas para essa metodologia de pesquisa em EA. O Grupo problematizou a metodologia através da explicitação de dúvidas e discussão do conceito de EA, da compreensão da pesquisa em EA como pesquisa qualitativa e dos limites e possibilidades da pesquisa-ação como modalidade de pesquisa em EA. Este artigo trata, portanto, dos temas debatidos, ampliando as reflexões a partir de questões referentes a essa metodologia colocadas pela prática e pela literatura na pesquisa em educação e em educação ambiental.

palavras-chave: Pesquisa qualitativa, Pesquisa-ação, Pesquisa-ação-participativa

abstract: The works carried out by the "Action Research" Discussion Group at the IV Research Meeting on Environmental Education - EPEA, July 2007, had as their starting point the debate on a reference text concerning the central issues of the action research methodology. The discussions occurred in two meetings during the event and pointed out features, limits and perspectives for the referred methodology in EE. The Group problematized the methodology by means of the display of doubts and the discussion of the EE concept, the comprehension of the qualitative nature of the research in EE, and the limits and possibilities of the action research as a research category in EE. Therefore, this article presents the themes discussed, enlarging the reflections through some issues related to the action research methodology that have been set by researches in education and environmental education, both in practice and literature.

keywords: Qualitative research, Action research, Participatory action research.

\section{Introdução}

Os trabalhos do Grupo de Discussão "Pesquisa e Ação" no IV Encontro de Pesquisa em Educação Ambiental - EPEA, em julho de

${ }^{1}$ UNESP - Instituto de Biociências/Botucatu - Departamento de Educação. Contato: mariliaedu@ibb.unesp.br 
2007, tiveram início na fase preparatória do evento. Pela Coordenação, elaborei um texto-base para discussão disponibilizado aos participantes do evento que se inscreveram no GD. O texto tinha como objetivo tratar das questões centrais do debate que a comunidade acadêmica vem realizando sobre a pesquisa-ação em educação ambiental como ponto de partida para as discussões. Essas discussões foram realizadas em dois encontros durante o evento e apontaram características, limites e perspectivas para essa metodologia de pesquisa em educação ambiental.

É preciso considerar, em primeiro lugar, que os participantes do GD eram, em sua maioria, participantes do evento sem muita experiência com a metodologia da pesquisa-ação, incluindo alguns com pouca ou nenhuma experiência em educação ambiental. Por esse motivo, a contribuição do Grupo para a pesquisa-ação se deu muito mais pela problematização da metodologia através da explicitação de dúvidas do que pela experiência coletiva. Assim, as principais questões trazidas pelo Grupo como contribuição para o debate sobre essa metodologia de pesquisa dizem respeito ao conceito de educação ambiental - respondendo, no debate, qual educação ambiental temos e queremos -, à compreensão da pesquisa em educação ambiental como pesquisa qualitativa - considerando que os pesquisadores em educação ambiental vêm de diversas áreas do conhecimento - e aos limites e possibilidades da pesquisa-ação como modalidade de pesquisa em educação ambiental na perspectiva de sua relevância científica e social.

Este artigo procura tratar, portanto, dos temas debatidos, tendo como ponto de partida o texto-base apresentado ao Grupo e as discussões empreendidas pelos seus membros, ampliando também as reflexões a partir de questões colocadas pela prática e pela literatura na pesquisa em educação e em educação ambiental que se referem a essa metodologia.

\section{Aproximação conceitual sobre educação ambiental}

As preocupações humanas com o ambiente estão presentes de forma mais consistente nas diferentes sociedades já há algumas décadas. Também dessa forma encontramos a inclusão da educação ambiental como estratégia na busca de sociedades ambientalmente mais responsáveis. 
No entanto, embora reconhecida como uma necessidade da sociedade contemporânea, seus princípios, objetivos e estratégias não são iguais para todos aqueles que a praticam, caracterizando, do ponto de vista conceitual, diferentes abordagens educativas. Podemos identificar algumas dessas diferentes abordagens como:

- disciplinatória-moralista, que orienta sua prática para "mudanças de comportamentos" ambientalmente inadequados, identificada também como "adestramento ambiental";

- ingênua-imobilista, que se pauta fundamentalmente pela "contemplação" da natureza, centrando o processo educativo na sensibilização ambiental;

- ativista-imediatista, que supervaloriza a ação imediata sobre o ambiente, substituindo o processo de ação-reflexão-ação pelo ativismo ambientalista;

- conteudista-racionalista, que orienta o processo educativo para a transmissão de conhecimentos técnicos científicos sobre o ambiente, considerando que essa transmissão/assimilação tem como conseqüência uma relação mais adequada dos sujeitos com o ambiente;

- crítica-transformadora, que concebe a educação ambiental como um processo político de apropriação crítica e reflexiva de conhecimentos, atitudes, valores e comportamentos que têm como objetivo a construção de uma sociedade sustentável nas dimensões ambiental e social.

Essas diferentes abordagens de educação ambiental indicam perspectivas adaptadoras-reprodutoras ou perspectivas transformadoras (TOZONI-REIS, 2007). A perspectiva adaptadora, caracterizada pela idéia de que a educação ambiental tem como tarefa a "adaptação" dos indivíduos a um "renovado" modelo de sociedade que, embora mais preocupado com o tema ambiental, não questiona o modelo de desenvolvimento em curso. Nessa perspectiva, com enfoques e estratégias diferentes (disciplinatória, ingênua, ativista e conteudista), tais abordagens contribuem para a reprodução das relações entre os grupos sociais e deles com o ambiente 
definidas pela modernidade. A perspectiva transformadora parte de análises críticas das relações entre os grupos sociais e deles com o ambiente em que vivem, compreendendo-as como relações históricas, cuja marca é a desigualdade social e a degradação ambiental. Essas diferentes perspectivas indicam que a ação educativa sobre o ambiente exige reflexão e análise para que, do ponto de vista prático e conceitual, seja construída de forma mais conseqüente e competente.

No entanto, nosso posicionamento a favor da educação ambiental crítica nos leva a pensar na necessidade de compreendê-la melhor. Nosso ponto de partida para definir a educação ambiental como crítica é sua preocupação com os aspectos socioambientais das relações humanas, isto é, preocupamo-nos com as relações que os sujeitos estabelecem entre si e com o ambiente onde vivem, compreendendo-os - sociedade e ambiente de forma crítica e transformadora. Podemos identificar aqui, portanto, a teoria crítica de interpretação da realidade como fundamento dessa abordagem na educação ambiental, cuja principal finalidade, segundo Loureiro (2005), é "construir conhecimentos que sirvam para a emancipação e para a transformação da sociedade".

Se a teoria crítica é uma forma de interpretar as relações sociais estabelecidas historicamente com o compromisso de contribuir para sua transformação, ela é a referência para a pedagogia crítica. Saviani (2005) afirma que a educação, na abordagem histórico-crítica, preocupa-se com a apropriação, pelos indivíduos singulares, dos saberes historicamente produzidos e que, "nessa nova formulação, a educação é entendida como mediação no seio da prática social global", de modo que "a prática social se põe, portanto, como ponto de partida e como ponto de chegada da prática educativa".

\section{A pesquisa qualitativa em educação}

Consideremos, então, em primeiro lugar, que educação ambiental é educação, o que nos leva a identificar como principal tarefa da pesquisa a produção de conhecimentos sobre os processos educativos ambientais. Isso significa dizer que o foco da produção de conhecimentos não são os temas ambientais gerais, mas o processo educativo voltado para 
a problematização do ambiente, isto é, o foco da produção de conhecimento é a educação para a formação humana que trate os temas ambientais em sua complexidade: conhecimentos sobre os processos educativos - inclusive na dimensão pedagógica - articulados às ciências ambientais. Consideremos também, em segundo lugar, que a produção de conhecimentos sobre um determinado fenômeno não é neutra. Então, se a abordagem que defendemos para a educação ambiental preocupa-se, fundamentalmente, com os aspectos socioambientais das relações humanas, compreendendo-os de forma crítica, transformadora e emancipatória, a pesquisa em educação ambiental tal como a compreendemos tem como principal objetivo produzir conhecimentos sobre processos educativos críticos com compromisso de transformação das relações sociais e ambientais na perspectiva da emancipação. Dessa forma, podemos afirmar que, se a educação ambiental é a ambientalização da educação, defendida aqui como crítica, transformadora e emancipatória, a tarefa da pesquisa em educação ambiental é produzir conhecimentos para esse processo de ambientalização da educação nessa perspectiva.

Lembremos então que, superando a tradição empirista da pesquisa científica, na educação a pesquisa tem abordagem qualitativa. Mas, para que essa afirmação tenha um significado mais claro para todos, vejamos seus argumentos. Sem necessariamente colocar em oposição pesquisa quantitativa e qualitativa, caracterizamos a pesquisa em educação como essencialmente qualitativa porque, na interpretação dos fenômenos educativos, preocupamo-nos em explorar as ações educativas desvelando uma realidade diversa, dinâmica, complexa e específica com o objetivo de compreender a realidade educativa da forma mais complexa e abrangente possível. Nesse sentido, essa realidade não pode ser somente quantificável: é preciso buscar, para a sua interpretação, a totalidade, entendida como complexidade, do fenômeno social e humano; é preciso buscar as "qualidades" dos processos educativos para compreendê-los. Isso significa dizer que a produção de conhecimentos sobre os processos educativos é a interpretação - estudada, fundamentada, analisada, refletida - da realidade investigada que, sem perspectiva de neutralidade, é vista a partir dos paradigmas pelos quais compreendemos as relações sociais e ambientais. 
Muito se tem discutido sobre a abordagem qualitativa da pesquisa em educação. Pesquisadores das áreas das ciências exatas e naturais tendem a desconsiderar essa abordagem como científica. No entanto, já avançamos bastante na idéia de que é preciso considerar que os fenômenos humanos e sociais são "um universo de significados, motivos, aspirações, crenças, valores e atitudes, o que corresponde a um espaço mais profundo das relações dos processos e dos fenômenos que não podem ser reduzidos à operacionalização de variáveis" (MINAYO, 2002). Na pesquisa qualitativa, portanto, a produção de conhecimentos sobre os fenômenos humanos e sociais está voltada muito mais para a compreensão dos fenômenos do que para a sua descrição.

Isso diz respeito aos paradigmas da investigação científica, aos paradigmas de interpretação da realidade. Se por paradigma entendemos o modelo teórico em que se fundamenta a ciência, seus pressupostos epistemológicos (KUHN, 2000), a insatisfação com os modelos teóricos dominantes na ciência moderna, hegemônicos no mundo acadêmico e científicos ainda hoje, tem mobilizado os esforços, teóricos e práticos, em direção à sua superação. Nas ciências humanas e sociais, no entanto, essas idéias não são novas: há muito se busca superar o paradigma dominante das ciências exatas e naturais em busca de novos referenciais para a interpretação da realidade humana e social.

É com essas preocupações que tratamos a pesquisa qualitativa em educação e suas contribuições para o processo educacional, uma tarefa filosófica para os pesquisadores da educação, que exige a localização da relação sujeito-objeto como preocupação central: compreender a relação sujeito-objeto é compreender como o ser humano se relaciona com as coisas, com a natureza, com a vida. A relação sujeito-objeto, na investigação científica, é um problema central em todas as ciências, mas compreendido diferentemente a partir de diferentes abordagens, que estão relacionadas às concepções de mundo, de ciência e de produção de conhecimentos que fundamentam as ações investigativas.

Sabemos das limitações - a rigor, da impossibilidade - das referências metodológicas das ciências naturais para o estudo dos fenômenos humanos e sociais. Essa impossibilidade é, no momento atual, suficientemente conhecida. Marx (1968), Capra (1993), Prigogine e Stengers 
(1997), Prigogine (1996), Morin (1999, 2002) e Morin, Ciurana e Motta (2003), entre outros, figuram como seus principais problematizadores. Outros autores e obras também têm colaborado nessa discussão, como Berman (1986), Santos (1989, 1995, 1997), Kuhn (2000) entre outros. Embora com idéias diferentes, o consenso teórico entre esses autores é a superação do paradigma mecanicista dominante na ciência moderna: vivemos uma nova concepção de ciência e de sociedade. A constatação de que a confiança epistemológica da ciência está abalada é o ponto de partida para a construção de uma nova forma de pensar e agir no mundo e na vida, para a construção de uma alternativa para a produção do conhecimento.

Isso significa que a pesquisa em educação tem caráter essencialmente qualitativo e, sem perder o rigor metodológico, busca compreender os diversos elementos dos fenômenos estudados. A educação, em particular, investiga os fenômenos educativos, seja na educação escolar ou na educação fora da escola, nos diferentes e diversos espaços educativos da vida cotidiana dos sujeitos educadores e educandos. Esses fenômenos, na abordagem qualitativa, somente serão compreendidos se examinados à luz de sua complexidade histórica, política, social e cultural. Desse modo teremos a garantia de produzir conhecimentos comprometidos com a educação crítica e transformadora.

Um ponto importante, portanto, a ser considerado na pesquisa em educação é a necessidade de garantir, na produção de conhecimentos sobre os processos educativos, qualidade metodológica, isto é, garantir à pesquisa em educação relevância científica. Abordagem qualitativa não significa falta de rigor científico, mas sim a busca de um rigor próprio, construído com base nas diferenças, bastante significativas, entre as referências científicas das ciências naturais e exatas e as referências científicas das ciências humanas e sociais.

Esse nosso compromisso, como pesquisadores em educação, de construir nossos próprios critérios de rigor científico nos traz a responsabilidade de elaborar metodologias de pesquisa relevantes para a investigação do fenômeno educativo, metodologias pautadas pelo rigor teórico. Compreendemos como rigor a preocupação com teorias e procedimentos metodológicos que, embora não tenham o objetivo de aprisionar os pesquisadores e a realidade pesquisada - cujos pressupostos 
de neutralidade e objetividade são por nós combatidos e superados - nos permitam traçar os caminhos de investigação que garantam legitimidade à produção dos conhecimentos sobre os processos educativos.

\section{A pesquisa-ação na educação ambiental}

Se, por um lado, é responsabilidade dos pesquisadores garantir relevância científica à pesquisa em educação e em educação ambiental, por outro, é nossa responsabilidade garantir relevância social aos processos de produção de conhecimentos. Retomemos o pressuposto de que os processos educativos ambientais - críticos e transformadores - são processos sócio-históricos. Então, tomemos a pesquisa sobre esses processos como uma "prática social de conhecimentos" (SANTOS, 1989). Assim, essa prática, por ser social, tem também significado sócio-histórico. A pesquisa em educação ambiental, portanto, implica escolhas políticas na produção dos conhecimentos sobre os processos educativos ambientais.

Com essas preocupações, podemos pensar, agora, nos princípios teórico-metodológicos dos processos educativos ambientais como forma de descobrir, neles, os princípios teórico-metodológicos da pesquisa em educação ambiental. A educação ambiental crítica e transformadora, educação emancipatória, tem caráter coletivo, dinâmico, complexo e contínuo de conscientização e participação social, articulando teoria e prática, marcada pela abordagem interdisciplinar (TOZONI-REIS, 2007).

Consideremos que o momento atual da pesquisa em educação ambiental caracteriza-se por produções teórico-metodológicas relacionadas às diferentes modalidades da pesquisa qualitativa conduzidas com o rigor metodológico exigido para que sejam legítimas. Nossas discussões acerca da importância da superação da tradição empirista da pesquisa científica indicam a necessidade de fazer a pesquisa em educação ambiental flexível, de forma a garantir criatividade nessa prática social. Nesse sentido, apontamos para processos de produção de conhecimentos que sejam originais, complexos e dinâmicos. Temos lançado mão da metodologia da pesquisa-ação na pesquisa em educação e na pesquisa em educação ambiental como caminho metodológico rico nessas possibilidades. 
No entanto, a pesquisa-ação tem sofrido uma certa desvalorização nos espaços acadêmicos. Essa desvalorização é resultado, por um lado, de sua própria banalização como metodologia de pesquisa e, por outro, de uma incompreensão - que chega a ser caracterizada como preconceito - de seu potencial investigativo do ponto de vista acadêmico-científico. Temos que reconhecer que alguns trabalhos anunciam essa metodologia como referência metodológica, mas não garantem rigor metodológico o suficiente para caracterizar as ações realizadas como um processo de investigação científica: apresentam, apenas, relatos de experiência em educação ambiental sem, pela análise, evidenciar a produção de conhecimentos exigida pela atividade de pesquisa. Dessa forma, sentimos a necessidade de aprofundar a reflexão sobre os aspectos metodológicos da pesquisa-ação.

Consideremos a necessidade de reconhecer o potencial investigativo da metodologia da pesquisa-ação. Esse potencial se expressa pela principal característica da metodologia, que permite - mais do que permitir, ela exige a articulação profunda e radical entre a produção de conhecimentos e a ação educativa. Isso significa dizer que a metodologia da pesquisa-ação refere-se a um tipo especial de produção de conhecimentos, comprometida com a açãointervenção no espaço social em que realiza a investigação. No caso da pesquisa-ação em educação, a compreensão, pela investigação, do fenômeno educativo articula-se à ação de educar, isto é, o fenômeno educativo é investigado no próprio processo de educar. Trata-se, portanto, de radicalizarmos na superação da neutralidade da pesquisa científica: o ato investigativo está comprometido, profundamente, com o ato educativo crítico, transformador e emancipatório.

Consideremos também o caráter político dessa intervenção educativa, que exige da pesquisa-ação a participação dos sujeitos envolvidos na produção de conhecimentos e na ação-intervenção: se a pesquisa-ação em educação ambiental refere-se a uma ação que tem por objetivo produzir conhecimentos sobre os processos educativos ambientais ao mesmo tempo em que realiza ações educativas ambientais, é preciso garantir, na pesquisa e na ação, a participação radical dos sujeitos. Nesse sentido, os participantes de um projeto de pesquisa-ação em educação ambiental deixam de ser "objetos" de pesquisa para realizarem-se como "sujeitos" da investigação científica e da ação educativa. A 
participação como princípio metodológico para a educação ambiental foi estudada por Jacobi (2005) como um "eixo estruturante", pois com isso podemos enfrentar a necessidade urgente de transformação nas relações da sociedade com o ambiente. Dessa forma, a pesquisa-ação toma uma dimensão profundamente participativa, e por isso consideramos muito mais apropriado definir essa metodologia como pesquisa-ação-participativa do que como pesquisa-ação. No entanto, essa é uma consideração que diz respeito à ênfase que pretendemos dar à participação, isto é, temos o cuidado de não distinguir, do ponto de vista de seus fundamentos teóricos, a pesquisa-ação das pesquisas participativas ou participantes, entendendo todas elas como expressões da possibilidade de articulação, na pesquisa, da participação radical dos sujeitos nos processos de produção de conhecimentos em educação ambiental, participação essa que compreendemos como a mais intensa possível em cada processo particular.

Uma outra consideração importante em nossas reflexões sobre essa metodologia diz respeito ao fato de que estamos nos referindo à produção de conhecimentos sobre a realidade, ao mesmo tempo em que ocorre um processo educativo participativo para o enfrentamento dessa mesma realidade. Então, é necessário considerar a própria realidade nessas reflexões. A pesquisa-ação-participativa é um processo de investigação e ação sobre uma determinada realidade, a "realidade concreta da vida cotidiana” (BRANDÃO, 2005b). Dessa afirmação emerge o caráter coletivo da pesquisa-ação-participativa. Assim, o estudo coletivo da realidade concreta da vida cotidiana, que, portanto, é participativo, implica, além disso, um processo educativo coletivo e emancipador. O grupo, como expressão do caráter coletivo da pesquisa-ação-participativa em educação ambiental, é considerado, conforme propõe Brandão (2005a), a "comunidade aprendente". Novamente aí a neutralidade da ciência é descartada: trata-se de uma ciência política e socialmente comprometida, uma modalidade alternativa de pesquisa qualitativa que coloca a ciência a serviço da emancipação social (DEMO, 1992). Nosso desafio é pesquisar e participar, investigar e educar, compreender e transformar.

As ações, investigativas e educativas, coletivas, participativas, emancipadoras, sobre a realidade concreta da vida cotidiana dos sujeitos podem ser expressas também pela idéia da educação como um processo de 
conscientização. Temos encontrado a relação entre educação e conscientização muito presente nas propostas de educação ambiental. No entanto, em muitas dessas propostas falta precisão conceitual no que diz respeito à conscientização. Paulo Freire (1921-1997) é a principal referência para compreender a educação como um processo de conscientização: para ele, ato ação-reflexão é a unidade dialética que define o termo conscientização:

Num primeiro momento a realidade não se dá aos homens como objeto cognoscível por sua consciência crítica. Noutros termos, na aproximação espontânea que o homem faz do mundo, a posição normal fundamental não é uma posição crítica mas uma posição ingênua. A este nível espontâneo, o homem ao aproximar-se da realidade faz simplesmente a experiência da realidade na qual está e procura. Essa tomada de consciência não é ainda a conscientização porque esta consiste no desenvolvimento crítico da tomada de consciência. A conscientização implica, pois, que ultrapassemos a esfera espontânea de apreensão da realidade, para chegarmos a uma esfera crítica na qual a realidade se dá como objeto cognoscível e na qual o homem assume uma posição epistemológica (FREIRE, 1980, p. 26).

Assim, vemos que conscientização, diferentemente da forma como a encontramos em muitas propostas de educação ambiental, é um processo de reflexão e ação com caráter essencialmente político, que implica escolhas políticas articulando conhecimentos e ação para a transformação das relações homem-natureza, relações estabelecidas pela história complexa da organização da vida social no ambiente. A educação ambiental, e sua prática social de conhecimento, a pesquisa e, em particular, a pesquisaação-participativa são compreendidas como mediadoras das relações sociais e se pretendem conscientizadoras porque propõem a relação entre a ação e a reflexão, que se concretiza, no processo educativo, na articulação entre conhecimentos, valores, atitudes e comportamentos. Conscientização é, portanto, uma dimensão do processo formativo construído ativa e refletidamente pelos sujeitos, um processo de construção de um nível de consciência que se pretende crítica. Nesse sentido, a conscientização supera a apropriação de conhecimentos, referindo-se à articulação radical 
entre conhecimento e ação, compreendendo a ação como uma ação política, transformadora, libertadora e emancipatória. Uma das mais importantes idéias aí é a compreensão do processo de conscientização como histórico e concreto, portanto, um processo que não é imediato, o que implica compreendê-lo para muito além do espaço e do tempo das ações educativas pontuais, específicas. Conscientização, como princípio da pesquisa-ação-participativa em educação ambiental, não se refere aos resultados empíricos das ações de investigação e ações educativas, tampouco à aquisição aparente de conhecimentos sobre o ambiente, mas refere-se ao processo, complexo, de reflexão filosófica e política, rumo à construção histórica, pelos sujeitos sociais, de uma sociedade sustentável.

A pesquisa-ação-participativa em educação ambiental, portanto, tem como princípios teórico-metodológicos a participação, o processo coletivo, a conscientização e, para ter relevância científica e social, refere-se também à articulação radical entre teoria e prática. Dito de outra forma: a pesquisa-ação-participativa em educação ambiental é práxis social. Tomemos os estudos de Konder (1992) sobre o "futuro da filosofia da práxis" como referência para nossas análises. Esse autor identifica a origem e a trajetória histórica do conceito de práxis desde a Grécia antiga, quando a palavra configurava-se, ainda que imprecisamente, em oposição a poiésis (atividade produtiva) e a theoria (a busca da verdade). Depois disso, é no Renascimento que a reflexão sobre o papel da reflexão da ação ganha destaque na nova organização da vida, agora na cidade. Pensando na sua importância na modernidade, quando vemos a valorização da ciência prática em detrimento da reflexão, constatamos que é com a desvalorização da teoria e a supervalorização da prática que se constrói a ciência moderna, base também do projeto educativo moderno. Continuando suas análises, Konder (1992) identifica em Marx um momento fundamental do estudo da práxis: este pensador, ao definir o trabalho como atividade essencial - vital - humana, o faz numa perspectiva de articulação radical entre teoria e prática. O conceito de práxis em Marx é definido como prática articulada à teoria, prática desenvolvida com e pelas abstrações do pensamento, como busca de compreensão mais consistente e conseqüente - concreta - da atividade prática humana: é prática eivada de teoria. Nesse sentido, a educação é práxis, é ação pensada, 
concreta, e a investigação sobre os processos educativos também tem essa perspectiva: articulação radical entre a teoria e a prática. É nessa perspectiva que podemos afirmar que o conceito de práxis é categoria central de análise da pesquisa-ação-participativa: a busca da compreensão da prática cotidiana pela ação-reflexão-ação.

Assim, a pesquisa-ação-participativa em educação ambiental é uma metodologia de investigação e ação sobre os processos formativos que tem como objetivo maior a formação do sujeito ecológico (CARVALHO, 2004), compreendendo-as (a investigação e a ação) como coletivas, participativas, conscientizadoras, emancipatórias e, principalmente, fundamentadas na práxis.

Para finalizar, tomemos de um texto escrito em outro momento (TOZONI-REIS, 2005) algumas diretrizes norteadoras para a pesquisaação-participativa em educação ambiental como facilitadoras de nosso trabalho:

- A proposta de investigação e ação caracteriza-se como atividade de pesquisa, isto é, relaciona-se à produção de conhecimentos ambientais e pedagógicos?

- A proposta de investigação e ação cria oportunidades reais e concretas de participação dos envolvidos, garantindo-lhes tomada de decisões coletivas em todo o processo?

- A proposta de investigação e ação é coletiva, compartilhada, caracteriza uma parceria entre o saber acadêmico e o saber não acadêmico?

- A proposta de investigação e ação desenvolve ações educativas ambientais de forma crítica e emancipatória, superando as tendências tradicionais de educação e ensino?

- A proposta de investigação e ação trata os temas ambientais de forma a tornarem-se temas geradores de reflexão e ação sobre o ambiente, contribuindo para o processo de conscientização? 


\section{Referências}

BERMAN, Marshall. Tudo que é sólido desmancha no ar. Trad. de Carlos Felipe Moisés e Ana Maria L. Ioriatti. São Paulo: Companhia das Letras, 1986.

BRANDÃO, Carlos Rodrigues. Comunidades aprendentes. In: FERRARO JÚNIOR, Luiz Antonio (Coord.). Encontros e caminhos: formação de educadoras(es) ambientais e coletivos educadores. Brasília: MMA, Diretoria de Educação Ambiental, 2005a. p.85-91.

Pesquisa participante. In: FERRARO JÚNIOR, Luiz Antonio (Coord.). Encontros e caminhos: formação de educadoras(es) ambientais e coletivos educadores. Brasília: MMA/Diretoria de Educação Ambiental, 2005b. p. 259-266.

CAPRA, Fritjof. O ponto de mutação: a ciência, a sociedade e a cultura emergente. 9. ed. Trad. de Álvaro Cabral. São Paulo: Cultrix, 1993.

CARVALHO, Isabel Cristina de Moura. Educação Ambiental: a formação do sujeito ecológico. São Paulo: Cortez, 2004.

DEMO, Pedro. Metodologia científica em ciências sociais. 2. ed. São Paulo: Atlas, 1992.

FREIRE, Paulo. Conscientização. São Paulo: Moraes, 1980.

JACOBI, Pedro. Participação. In: FERRARO JÚNIOR, Luiz Antonio (Coord.). Encontros e caminhos: formação de educadoras(es) ambientais e coletivos educadores. Brasília: MMA/Diretoria de Educação Ambiental, 2005. p. 231-236.

KONDER, Leandro. O futuro da Filosofia da práxis: o pensamento de Marx no século XXI. 3. ed. Rio de Janeiro: Paz e Terra, 1992.

KUHN, Thomas. A estrutura das revoluções científicas. 5. ed. Trad. de Beatriz Vianna Boeira e Nelson Boeira. São Paulo: Perspectiva, 2000.

LOUREIRO, Carlos Frederico B. Teoria Crítica. In: FERRARO JÚNIOR, Luiz Antonio (Coord.). Encontros e caminhos: formação de educadoras(es) ambientais e coletivos educadores. Brasília: MMA/Diretoria de Educação Ambiental, 2005. p. 325-332.

MARX, Karl. O Capital: crítica da economia política. Trad. de Reginaldo Sant'Anna. Rio de Janeiro: Civilização Brasileira, 1968.

MINAYO, Maria Cecília. Pesquisa Social: teoria, método e criatividade. Petrópolis: Vozes, 2002.

MORIN, Edgar. Ciência com consciência. 6. ed. Trad. de Maria D. Alexandre e Maria Alice Sampaio Dória. Rio de Janeiro: Bertrand Brasil, 2002.

O paradigma perdido: a natureza humana. 6. ed. Trad. de Hermano Neves. Lisboa: Publicações Europa-América, 1999.

MORIN, Edgar; CIURANA, Emilio-Roger; MOTTA, Raúl Domingo. Educar na era planetária. O pensamento complexo como método de aprendizagem pelo erro e incerteza humana. Trad. de Sandra Trabucco Valenzuela. São Paulo: Cortez; Brasília: UNESCO, 2003.

PRIGOGINE, Ilya. O fim da ciência? In: SCHNITMAN, Dora Fried (Org.). Novos paradigmas, cultura e subjetividade. Trad. de Jussara Haubert Rodrigues. Porto Alegre: Artes Médicas, 1996. p. 25-40. 
PRIGOGINE, Ilya; STENGERS, Isabelle. A nova aliança. 3. ed. Trad. de Miguel Faria e Maria Joaquina Machado Trincheira. Brasília: Editora da UnB, 1997.

SANTOS, Boaventura de Sousa. Introdução a uma ciência pós-moderna. Rio de Janeiro: Graal, 1989. Cortez, 1997.

Pela mão de Alice: o social e o político na pós-modernidade. 4. ed. São Paulo: Um discurso sobre as ciências. Lisboa: Afrontamento, 1995.

SAVIANI, Dermeval. Pedagogia bistórico-crítica. Campinas: Autores Associados, 2005.

TOZONI-REIS, Marília Freitas de Campos. Compartilhando saberes: pesquisa ação educativa ambiental. In: FERRARO JÚNIOR, Luiz Antonio (Coord.). Encontros e caminhos: formação de educadoras(es) ambientais e coletivos educadores. Brasília: MMA, Diretoria de Educação Ambiental, 2005. p. 269-276.

Pesquisa-ação-participativa e a educação ambiental: uma parceria construída pela identificação teórica e metodológica. In: ___ (Org.). Pesquisa-ação-participativa em educação ambiental: reflexões teóricas. São Paulo: Annablume, 2007.

Artigo recebido em 16/11/2007 - Aprovado em 04/06/2008 
